\title{
A cloud-based MODFLOW service for aquifer management decision support
}

\author{
David Jones \\ Norm Jones \\ Brigham Young University - Provo, njones@byu.edu \\ James Greer \\ Jim Nelson \\ Brigham Young University - Provo
}

Follow this and additional works at: https://scholarsarchive.byu.edu/facpub

Part of the Other Civil and Environmental Engineering Commons

\section{Original Publication Citation}

Jones, David, Norm Jones, James Greer, and Jim Nelson, "A cloud-based MODFLOW service for aquifer management decision support," Computers and GeoSciences, Vol. 78, pp. 81-87, 2015.

\section{BYU ScholarsArchive Citation}

Jones, David; Jones, Norm; Greer, James; and Nelson, Jim, "A cloud-based MODFLOW service for aquifer management decision support" (2015). Faculty Publications. 4277.

https://scholarsarchive.byu.edu/facpub/4277

This Peer-Reviewed Article is brought to you for free and open access by BYU ScholarsArchive. It has been accepted for inclusion in Faculty Publications by an authorized administrator of BYU ScholarsArchive. For more information, please contact ellen_amatangelo@byu.edu. 


\title{
A cloud-based MODFLOW service for aquifer management decision support
}

\author{
David Jones ${ }^{\mathrm{a}}$, Norm Jones ${ }^{\mathrm{b}, *}$, James Greer $^{\mathrm{c}}$, Jim Nelson ${ }^{\mathrm{d}}$ \\ ${ }^{a}$ Utah Division of Water Rights, 1594 W North Temple, Suite 220, Salt Lake City, UT 84114-6300, United States \\ ${ }^{\mathrm{b}}$ Brigham Young University, 242 L Clyde Building, Provo, UT 84602, United States \\ ' Utah Division of Water Rights, 1594 W North Temple, Suite 220, Salt Lake City, UT 84114-6300, United States \\ ${ }^{\mathrm{d}}$ Brigham Young University, $242 \mathrm{~K}$ Clyde Building, Provo, UT 84602, United States
}

\section{A R T I C L E I N F O}

\section{Article history:}

Received 24 April 2014

Received in revised form

23 December 2014

Accepted 20 February 2015

Available online 21 February 2015

\section{Keywords:}

Groundwater management

Groundwater modeling

Cloud computing

MODFLOW

\begin{abstract}
A B S T R A C T
A framework to publish simplified MODFLOW groundwater modeling capabilities to a web interface for use by water managers and stakeholders is presented. Numerical modeling simulations can assist aquifer management decisions, but the amount of time and professional expertise required to wield modern groundwater models often exceeds the resources of regulating agencies - even for simple modeling tasks that are repetitive in nature. The framework is capable of automating such modeling tasks, accepting user input, executing MODFLOW, and generating specialized results including maps and modeling reports. This framework was used to build a pilot system for an aquifer in central Utah, allowing a user to simulate the effects of proposed well diversions. This prototype system allows a user to input properties for any number of candidate wells, execute an associated MODFLOW model, and view drawdown contours and regions of decreased spring flow on a web map interface. The modeling analysis is cast into a geoprocessing workflow using ArcGIS and Arc Hydro Groundwater tools, and then made accessible from a server. Such automated and accessible modeling systems have promising potential to facilitate efficient groundwater resources management and reduce modeling errors.
\end{abstract}

c) 2015 Elsevier Ltd. All rights reserved.

\section{Introduction}

Water resource managers are faced with the difficult task of satisfying a growing demand for fresh water with a static, and sometimes declining, supply. Groundwater has often been tapped as a convenient and accessible resource for satisfying demand, especially during drought cycles. Unfortunately, many aquifers have been over-allocated, leading to aquifer subsidence, decreased water quality, and increased costs associated with pumping from greater depths and deepening existing wells (Changming et al., 2001; Galloway et al., 1999; Konikow and Kendy, 2005). These issues have generated increasing pressure on water managers to develop more sophisticated techniques for managing aquifers in a sustainable fashion. Judicious management of groundwater resources demands that high quality information be placed in the hands of decision makers. Modern groundwater modeling techniques are often used for water system forecasting, yet these modeling analyses are usually accessible only at the high cost of

\footnotetext{
* Corresponding author.

E-mail addresses: d2j15@yahoo.com (D. Jones), njones@byu.edu (N. Jones), jamesgreer@utah.gov (J. Greer), jimn@byu.edu (J. Nelson).
}

dedicated modeling professionals.

To obtain projections of future aquifer conditions in response to a set of proposed changes, water agencies both in the United States and abroad often use MODFLOW models. Once a regional model is developed and calibrated, modelers may analyze the effects of a proposed policy or water diversion change by altering and executing the model. Recognizing the repetitive nature of many of these modeling tasks, Jones et al. developed a strategy to automate the process (Jones et al., 2010a, 2010b). We build on that effort, showing how an automated MODFLOW process can be published to a web interface for direct use by water management professionals.

In recent years, the development of cyberinfrastructure for sharing of water resources data and simulation tools via web services and shared online databases has been the focus of considerable research (Ames et al., 2012; Castronova et al., 2013; Castronova and Goodall, 2010; Diaz et al., 2007; Glenis et al., 2013; Horsburgh et al., 2008, 2009). Recent efforts have demonstrated the utility of cloud-based decision support systems that integrate historic and current water data into a single, easily accessible web interface enhanced with interactive mapping capabilities (Dymond et al., 2004; Glenis et al., 2013; Oulidi et al., 2012; Refsgaard et al., 2010; Tillman et al., 2007). In the case of 
groundwater, most of these systems are for data mapping and analysis, but are not designed to run MODFLOW models. Liu et al. (2010) recently developed a system for running MODFLOW models on a commercial cloud. However, it is primarily designed for enabling easily scalable distributed computing for cases involving large batch runs, such as stochastic analyses. In this paper, we demonstrate a new scripting framework that enables agencies to develop automated systems for modifying and executing MODFLOW models on the cloud via a web interface in support of groundwater management.

The Utah Division of Water Rights (UT-DWR) is responsible for authorizing all groundwater diversion in Utah. To analyze groundwater impacts due to a proposed water right change, UTDWR has collected several MODFLOW models covering most of the major aquifers in the state. Unfortunately, modifying and running these models for every application that must be evaluated is unfeasible; it simply takes too much time from the few engineers capable of building models and interpreting results. To address this problem, we have developed a pilot cloud-based system to assist the UT-DWR in evaluating the impacts of proposed groundwater extraction changes in Northern Utah Valley (Jones, 2012). The automation provided by this system significantly reduces the time and effort required to perform a groundwater simulation as part of a water rights review, thereby allowing experts to use models as an aid in the decision-making process in a greater number of cases.

\section{System overview}

The cloud-based analysis system may be divided into three successively encapsulating components: a MODFLOW model, an ArcGIS geoprocessing workflow, and a web interface (Fig. 1). Arc Hydro Groundwater (AHGW) tools allow the geoprocessing workflow to encapsulate the MODFLOW model, and a web service allows users of the web interface to execute the geoprocessing workflow.

The Northern Utah Valley MODFLOW model which was created and recently updated by the USGS (Cederberg et al., 2009) was chosen as the pilot application. It is a steady state model with multiple confining units represented by four layers. While the following description of these components will specifically discuss the pilot application, the system can be adapted to enable similar geoprocessing workflows to be developed to automate any MODFLOW simulation. Furthermore the overall organization could potentially be used for other simulation programs.

\subsection{Arc Hydro Groundwater}

AHGW is an ArcGIS extension that offers geoprocessing tools and a standardized database schema to maintain hydrogeological data with GIS (Strassberg, 2005; Strassberg and Jones, 2010; Strassberg et al., 2007, 2011). MODFLOW Analyst is a subset of the AHGW tools that allows MODFLOW models to be stored, modified, and executed from an ArcGIS platform such as ArcMap or ArcGIS Server. It can be used to transfer model data from native MODFLOW input files to a geodatabase that has been formulated using an extension of the AHGW data model called the MODFLOW Data Model (Jones and Strassberg, 2008). After the geodatabase is populated, AHGW tools in tandem with standard ArcGIS operations may be used to modify and run models, and visualize the model inputs and outputs (Jones et al., 2011). This approach to groundwater modeling enables modelers to (1) automate common modeling tasks with scripted workflows and (2) leverage the sophisticated mapping capabilities of ArcGIS. The cloud-based system capitalizes on both of these features.

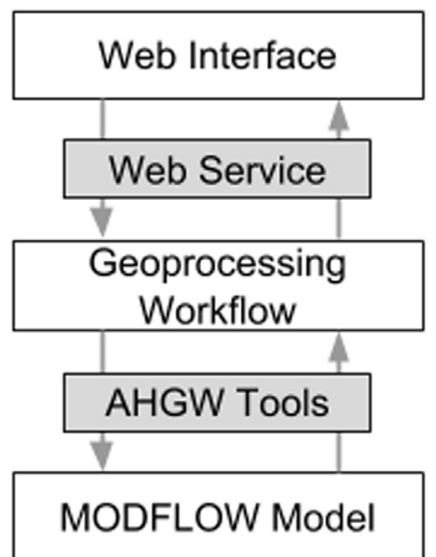

Fig. 1. Data flow schematic showing components used for the Northern Utah Valley system.

\subsection{Geoprocessing workflow}

The geoprocessing workflow refers to a program that calls the sequence of geoprocessing tools to perform the MODFLOW analysis. The workflow may be expressed using Python or any programming language that complies with requirements of the web service and is capable of executing ArcGIS geoprocessing tools. Regardless of the implementation, the workflow automates the operations required to (1) properly modify MODFLOW input files, (2) run the model, (3) interpret the resulting output files into meaningful ArcGIS features, (4) save maps of the result features in formats suitable for archival and web mapping, such as PDF and KML files. As the script is executed, status messages communicate the progress of the workflow to the web interface.

For the pilot system performing a well-permitting analysis, the MODFLOW input files are modified to include elements representing well applications. Two indicators, aquifer drawdown and the change in discharge of springs feeding Utah Lake, are the results the analysis derives to evaluate impacts. A simplified representation of this pilot workflow is shown in Fig. 2 with a detailed discussion following.

1. Modify model: The geoprocessing workflow requires input arguments defining the coordinates, screen elevations, and pumping rate for each candidate well associated with a permit application. The Create MODFLOW Well Records tool appends this candidate well input information to a table of all MODFLOW well features, and the Export Package WEL tool formulates the WEL file using this amalgamated table. With the newly generated WEL file, the MODFLOW simulation is ready to be executed.

2. Execute model: The execution of the MODFLOW simulation is performed with a single AHGW tool, Run MODFLOW. This tool requires two input parameters: the path to the MODFLOW name file, and the path to the executable. A MODFLOW executable file is downloaded with the AHGW tools and may be copied into an accessible directory.

3. Interpret model results: After MODFLOW executes, the workflow begins reading the model output files and creating features to represent drawdown and the change in spring discharge. The Import MODFLOW Output tool populates one table with the calculated drawdown for each cell, and populates another table with the calculated flows through each drain element. The Create MODFLOW Features tool then joins the drawdown table with point geometries representing the two-dimensional cell center of the MODFLOW grid. Standard geographic tools may then be used to generate lines of equal drawdown from these results. 


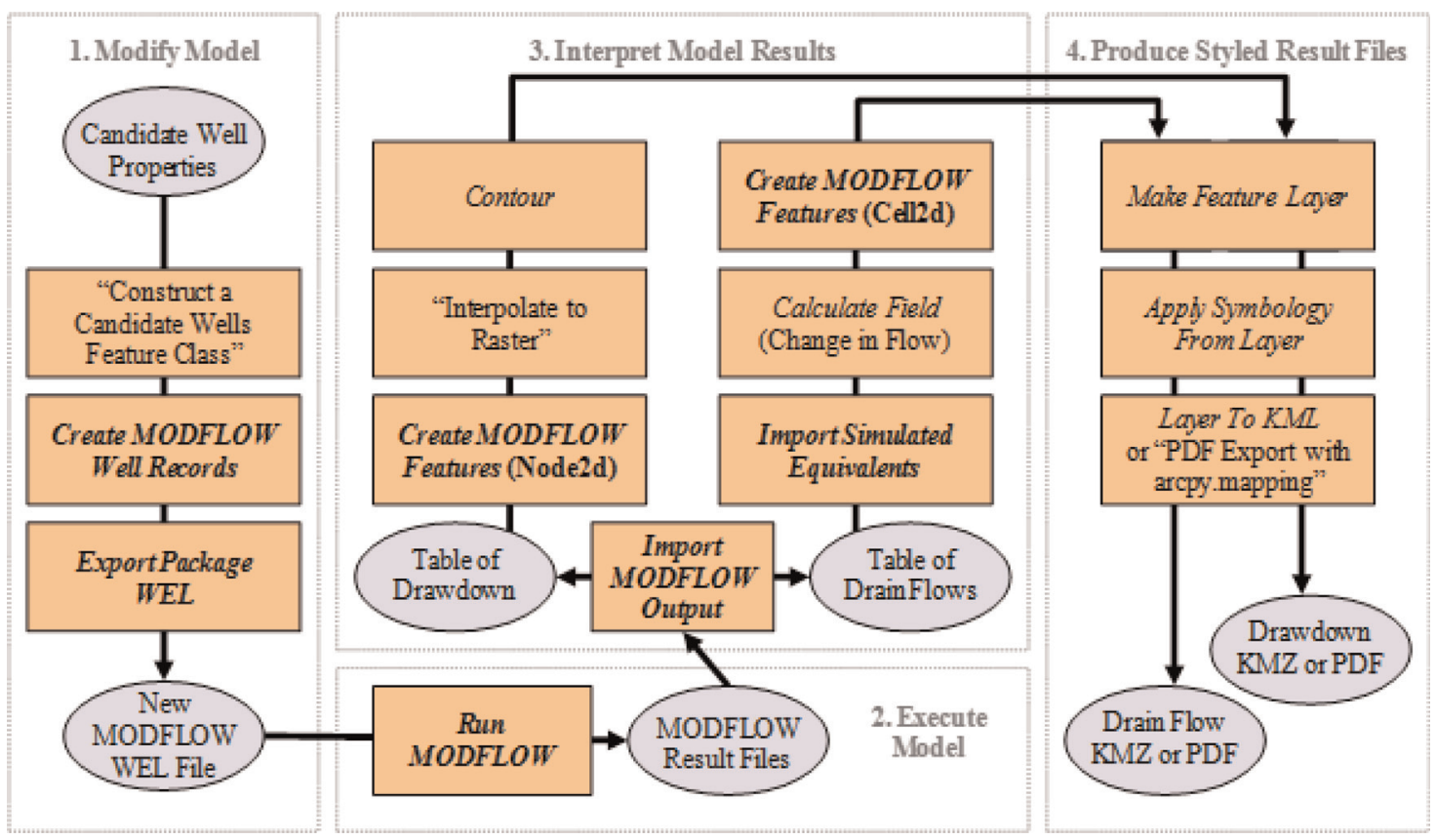

Fig. 2. Simplified geoprocessing workflow for MODFLOW well permitting analysis.

To obtain the change in spring flows, the workflow uses the Import Simulated Equivalents tool to populate the FLOB table with the simulated drain flows. The FLOB table is associated with the Observation (OBS) Process in MODFLOW. Although the FLOB table is meant to store flow observation data for parameter estimation runs, it may be pre-populated with the baseline flows rather than flow observations as a method to obtain flow changes. The changes in flow resulting from the new wells are then listed as residual flows, the difference between simulated and "observed" as determined with the Calculate Field tool. The Join Field tool appends a set of integer values which indicate which layer each drain belongs to. The next tool, Create MODFLOW Features, turns the table into a geographic feature class, joining the tabular data to polygon representations of MODFLOW cells.

4. Produce styled result files: The results of the analysis include geographic data that will be displayed on a web map. For the pilot application, we found it advantageous to produce these results as KML files. This format supports self-contained symbology and attributes, is supported by several viewer applications, and may be incorporated into a workflow with the standard Apply Symbology From Layer and Layer to KML geoprocessing tools.

The PDF Export geoprocessing tool can produce print quality PDF maps of the analysis results. Multiple PDF map documents may be appended into a single report for permanent archival. First, the resultant feature class - in this case the drawdown contour lines and the change in spring flow polygons - must be converted to an ArcGIS layer file using Make Feature Layer. The appearance of features in the layer file can be controlled with Apply Symbology From Layer. This tool allows a color scale to be applied to the result features to expose extreme results. A workflow expressed using Python may using functions in the arcpy.mapping module to add the formatted layer file to a pre-created template map document, adjust the positioning and text of map elements, and save the resulting document as a PDF file. If the template map document includes a legend element, the symbols of layers that are added to the map will appear in the legend of the PDF file.

As the workflow is executed, status messages reassure the user of the progress of the workflow and report the results. The pilot workflow writes these messages to a text file which the web interface reads at regular intervals. This text file allows not only the progress of the workflow to be communicated, but also the URLs of the result files.

\subsection{Web service}

The web service component allows a remote user to provide input to the analysis and receive its results. Execution of a geoprocessing workflow is compute-intensive and requires more resources than the familiar class of web services that retrieve stored data with minimal processing. The pilot system does not represent an effort to create a sophisticated web service capable of handling a high frequency of requests; rather, it is based on a rudimentary web service involving a single PHP script hosted by a single server. This service is designed for a stand-alone application system; since the web interface provides much of the functionality essential for a decision support system, no effort was made to conform to established standards that would allow the service to be easily used by other client applications. More distributed systems may call for an alternate approach. For example, UT-DWR has utilized ArcGIS Server software to create and manage geoprocessing web services for their implementation.

While some service design decisions are specific to the needs and scale of the decision support system, the compute-intensive nature of a modeling service requires special attention. Execution of a geoprocessing workflow is compute-intensive and requires more resources than the familiar class of web services that retrieve stored data with minimal processing. The custom service was designed to report progress messages to be relayed to the user, providing notice of the status of the simulation execution.

\subsection{Web interface}

A web mapping interface was designed to allow a user to run the well permitting tool and interact with the results (Fig. 3). Prior to executing an analysis, the "Table of Well Applications" tab is used to add a new well or set of wells to a candidate well database implemented with MySQL. A set of simple user forms is used to enter the $X Y$ coordinates of each well and the well properties, 


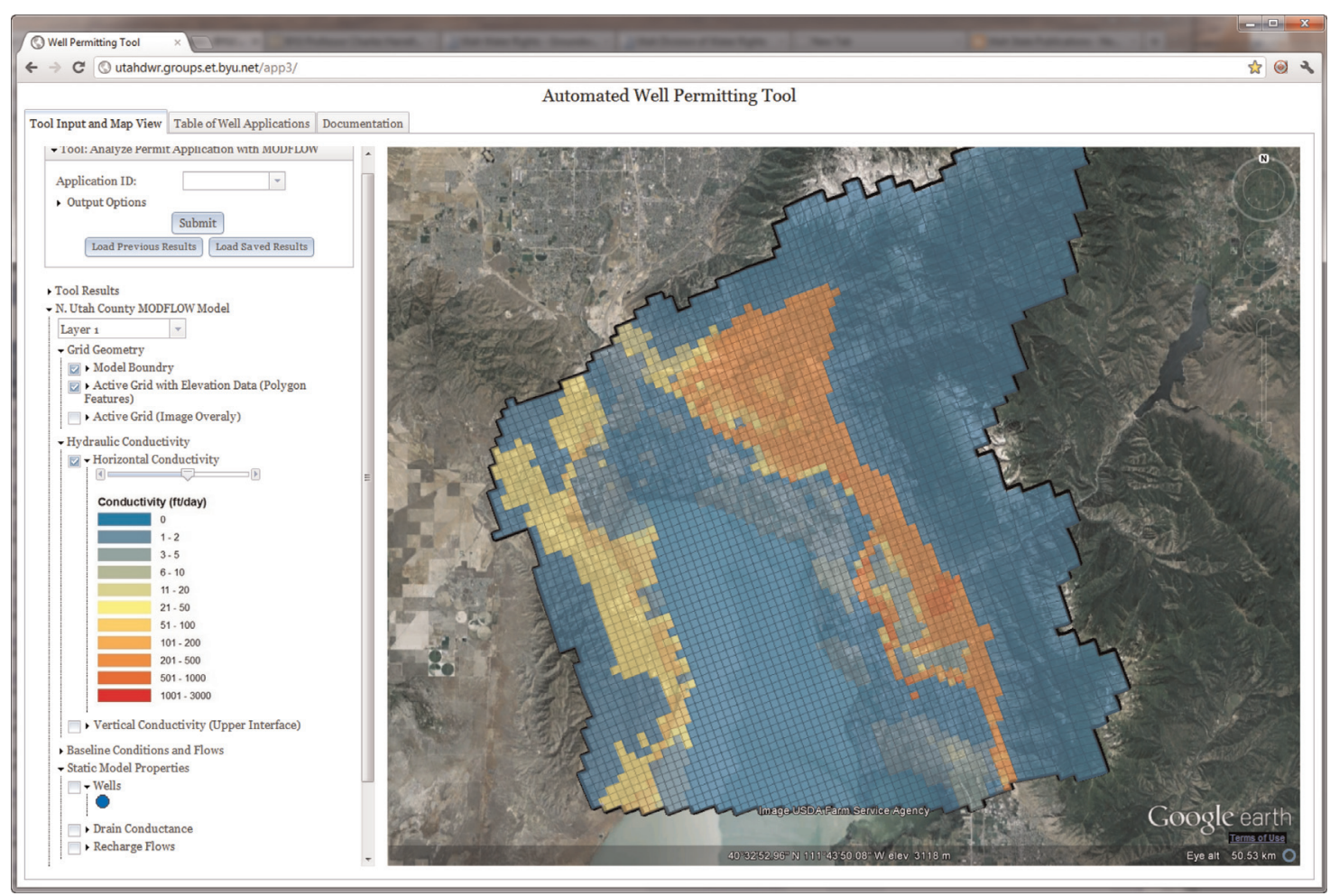

Fig. 3. Web interface for cloud-based well permitting system.

including the pumping rate. Each well is also given an Application ID, which uniquely identifies the set of wells associated with an application. Once this process is complete, the form components on the "Tool Input and Map View" tab are used to initiate an analysis. The user selects the set of wells to be analyzed by choosing a unique Application ID from a list all of the unique IDs in the candidate well database. A set of output options is selected and the Submit button launches the Python geoprocessing workflow described in Section 2.2. A typical analysis takes several minutes to complete, during which messages indicating the status and progress of the script are displayed in the window on the left side of the browser. For applications involving longer simulation times, it would be possible to modify the script to provide an e-mail or text message notification of the script completion. Once the simulation is finished, the KML components of the simulation output are loaded into the Google Earth map and the components are listed in the "Tool Results" section so that they can be toggled on and off. The KML map layers include water table contours, drawdown contours, and maps indicating change in discharge to springs. The Tool Results section also includes a link to a PDF file that can be downloaded by the user. This file contains a highly detailed set of report-ready maps and tables associated with analysis results.

The web interface developed for the pilot application makes use of web mapping capabilities to display simulation inputs and results. Of many available web mapping clients that provide a responsive user experience, we decided to employ a Google Earth web map. This principal advantage of this mapping platform over alternatives such as the traditional Google Maps API, ESRI JavaScript API, and the ESRI Flex API is the large number of reference layers that may easily be added to the map in KML format. Reference layers are of great importance to the web interface because they allow the user to realize the meaning of the simulation results. For example, when a user is able to superimpose the model results with a reference layer that displays the location of existing water rights, that user can then easily identify the exiting water users that might be impacted by the application. Other reference layers showing information about the MODFLOW model may assist the proper interpretation of the results. For example, a reference layer displaying the model active boundary would allow a user to understand the reason for model results truncating at the edge of the model domain. A reference layer showing the model grid would allow a user to identify the spatial resolution of the model. Similarly, reference layers showing baseline heads, hydraulic conductivity, and locations of model sources and sinks would be useful.

Using reference layers in KML format allows feature symbology and pop-up window content to be saved with the feature geometry in a manner that can be edited or previewed with external software. Since the selected web mapping clients supports adding KML files, the coding effort to parse and display KML reference layers is minimal. While several web mapping clients provide some support for adding KML dataset, all except the Google Earth web client impose restrictive file size limitations.

The interface was designed to work in all common browsers. It aims to provide a refined user experience by leveraging Ajax techniques rather than page reloads, allowing a user to submit a simulation request, monitor progress messages, and view results without navigating between multiple pages. Of the many JavaScript libraries that could assist in obtaining this consistent and responsive behavior, the Dojo Toolkit JavaScript library was selected. This library is used extensively by developers creating web maps with the ESRI JavaScript API, and plenty of online coding resources are available.

\subsection{Software components}

As described above, the foundation for the well-permitting system is a set of custom Python scripts. These scripts utilize a set of geoprocessing tools within ArcGIS and the AHGW extension, both of which are proprietary products. The other tools in the system (Ajax, Dojo, and Google Earth) utilize HTML, PHP, and Javascript and are free for non-commercial use. Google enforces a 
usage limit of 25,000 map loads per day, which should not be a functional limitation for most implementations (Google, 2014). All of the custom code associated with this project, including the Python, HTML, PHP, and Javascript tools are free and open source and can be downloaded from the Computers and Geosciences GitHub repository (GitHub, 2014).

\section{Case study}

A case study was developed to demonstrate the utility of the tools and applied to retrospectively analyze a previous water right application of the North Utah County MODFLOW simulation. In December of 2009, the City of Saratoga Springs submitted an "Application for Permanent Change of Water," desiring to transfer rights to divert 450 acre-ft/yr $\left(555,000 \mathrm{~m}^{3} / \mathrm{yr}\right)$ of water from four agricultural wells southeast of Utah Lake to 11 municipal wells northeast of Utah Lake. In response to this proposal, several parties submitted formal notices of protest, arguing the change would harm neighboring water users by depleting the aquifer and decreasing flows in the Jordan River.

The change application was processed without the aid of a groundwater numerical model simulation. UT-DWR applied the safe yield criteria set forth in the region's groundwater management plan to dismiss the concern of unsustainable aquifer drawdown, and the division referred to a USGS technical publication characterizing the local aquifer to evaluate the possibility that Jordan River flows would be diminished. The change was approved with the condition that Saratoga Springs would monitor return flows to ensure depletion remained below historic levels. This retrospective case study will demonstrate how quantitative forecasts from a cloud-based groundwater simulation may enhance the water manager's decision-making process.

Prior to running the cloud-based version of the MODFLOW model, the new well locations and attributes were added to the candidate well database using the web interface. In a typical scenario such as this where the applicant wishes to relocate existing groundwater rights, one would first account for the cessation of water diversion at the original locations by adding a copy of the wells at these locations with mirrored pumping rates to simulate the removal of the wells from the base model. Because of the great distance between the original wells southeast of Utah Lake and the proposed wells northeast of Utah Lake, only the proposed wells at the new locations were included. The tool requires each candidate well's latitude, longitude, pumping rate, and screen top and bottom elevations. Lacking details on how the yearly water allotment would be distributed among the 11 proposed wells, the analysis was performed assuming a uniformly distributed pumping rate of $4882 \mathrm{ft}^{3} /$ day (138.2 $\mathrm{m}^{3} /$ day) for each well. Because screen elevation data was unavailable, these elevations were estimated so that the resulting wells would be placed in MODFLOW layer 3, a relatively thick, conductive, and accessible layer. Of course, a rigorous analysis might account for such unknowns by considering multiple simulations with varying assumptions.

After the required well parameters were established and entered into the database, the tool for running MODFLOW was accessed with a web browser. The corresponding Application ID and a drawdown contour interval of $0.2 \mathrm{ft}(6.1 \mathrm{~cm})$ were entered in the tool input forms. Several minutes after the simulation was submitted for processing on the server, KML result layers depicting calculated drawdown and spring flow change were added to the map. As expected, the greatest drawdown and spring flow decreases near the proposed wells were found in MODFLOW layer 3, the layer where the wells were placed due to the screen elevation assumptions. The largest computed drawdown contour was $1.6 \mathrm{ft}$ $(0.5 \mathrm{~m})$ and the total decrease in spring flows was $16,552 \mathrm{ft}^{3} /$ day ( $469 \mathrm{~m}^{3} /$ day). The spatial distributions of these impacts, as mapped by the web application, are illustrated by Fig. 4. Springs adjacent to Utah Lake are simulated with the MODFLOW Drain Package. If the water table elevation is below the spring elevation, no discharge occurs. If the water table is above the spring elevation, discharge is proportion to the head difference (water table elevation minus the spring elevation) multiplied by a conductance factor. The colored cells in the figure on the right side correspond to drain package cells.

The drawdown contours overlain with the locations of neighboring wells and other points of authorized water diversion are shown in Fig. 5. An info-balloon of a well belonging to a protestant is shown; judging by its location between contour lines, the expected drawdown at this neighboring well is $0.7 \mathrm{ft}(0.2 \mathrm{~m})$.

Additional web application map layers were available to verify the reasonableness of the case study results: the drawdown contours were compared with a map layer showing model conductivity values, the spring flow results were consistent with a map layer of drain element conductance, and the model spatial resolution was described with a map layer illustrating the
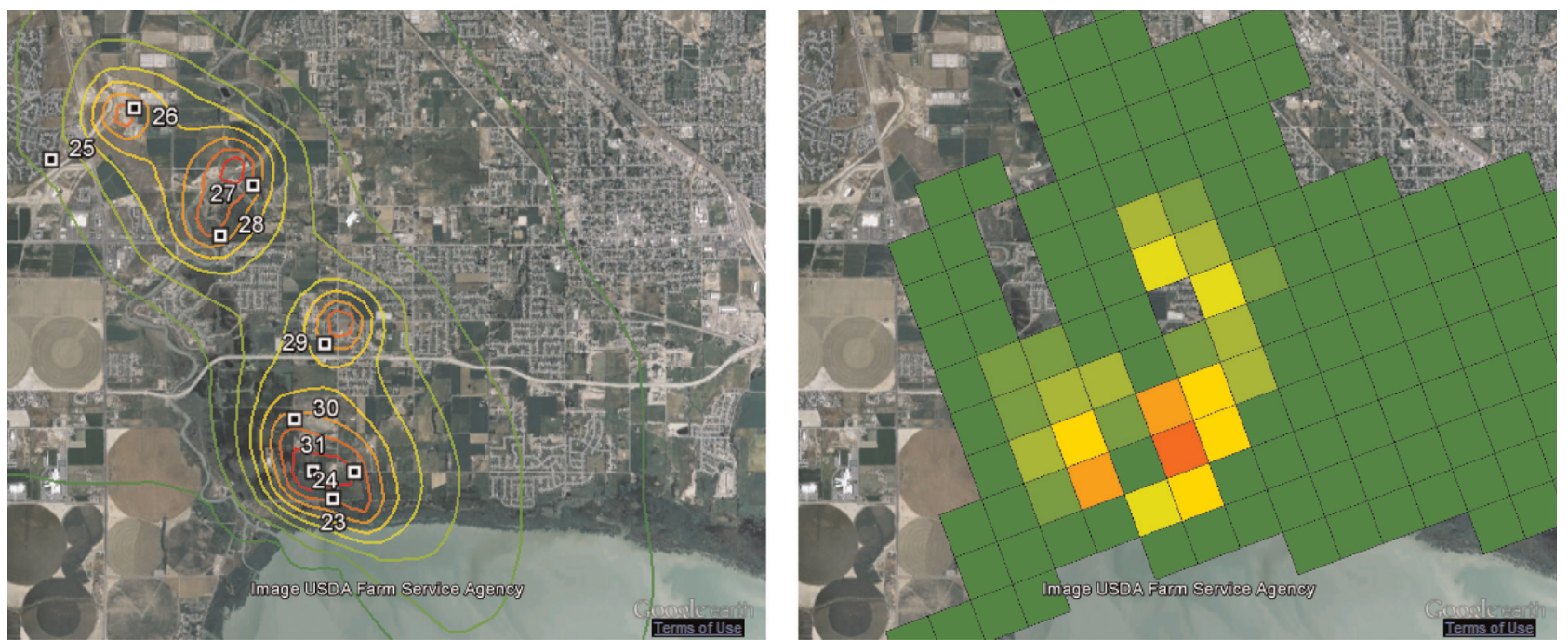

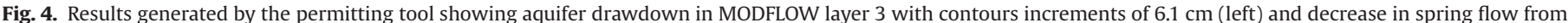
MODFLOW layer 3 (right). (For interpretation of the references to color in this figure, the reader is referred to the web version of this article.) 


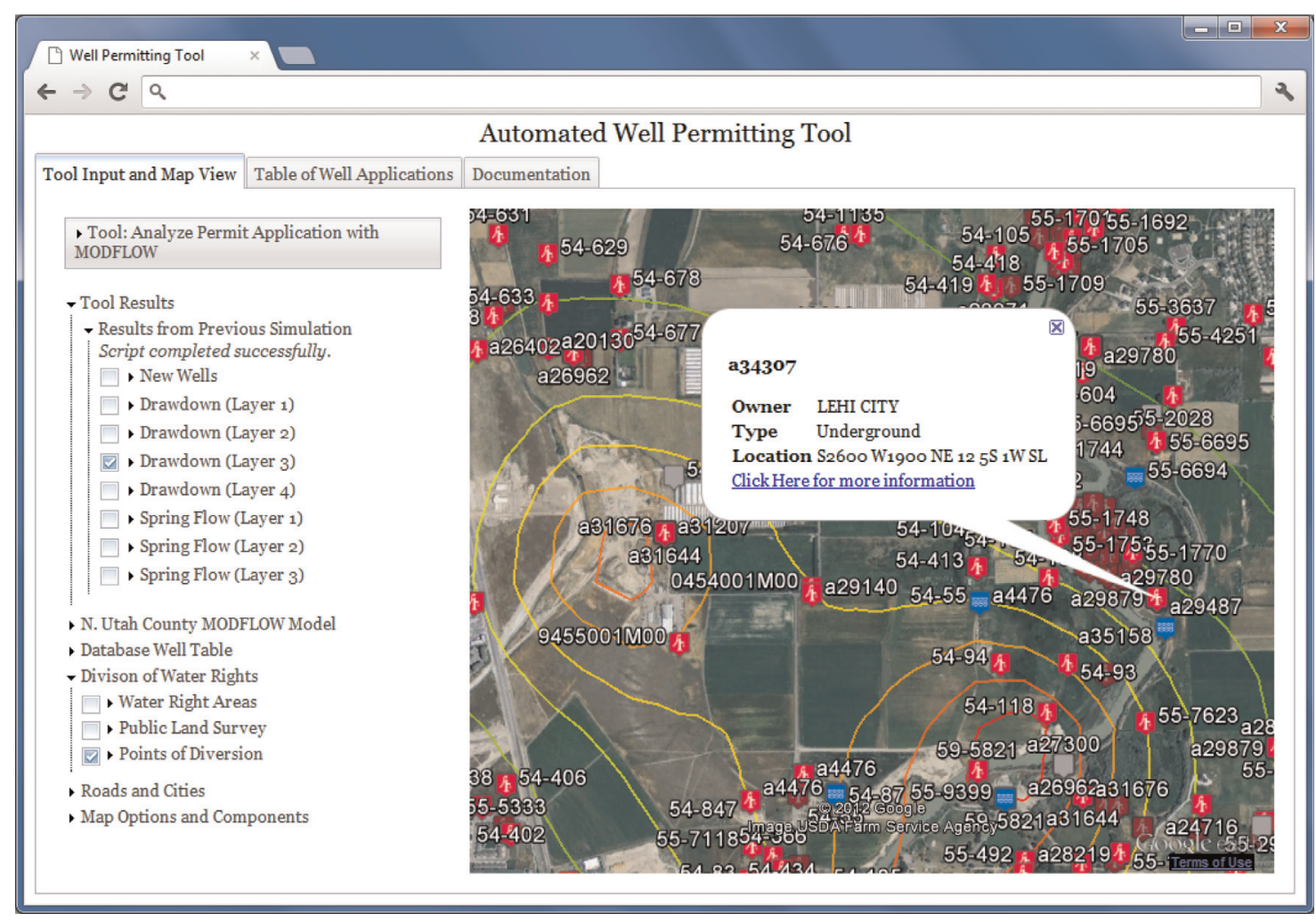

Fig. 5. Drawdown results superimposed with map of existing wells.

MODFLOW grid discretization.

Interpretation of the simulation results indicates only mild drawdown would be expected at neighboring wells. This information could have been used to respond to the protestants' concerned with head loss at their wells. The results also validate the concern that the change would decrease Jordan River flows if the original diversion rate was permitted and provide an estimate of the magnitude of that change based on impacts to springs. This change is relatively small and would be mitigated by increased discharge on the opposite side of the lake by the decommissioned wells. In summary, the case study results would have provided additional evidence defending the decision to approve the change application.

\section{Conclusions}

As described in the introduction, water managers are under increasing pressure to manage groundwater resources in a sustainable fashion. This warrants a very careful analysis of impact of each application for groundwater withdrawals, utilizing the best modeling and analysis tools available. At the same time, a large number of applications must be reviewed on an annual basis. It is simply not feasible in most cases to run a MODFLOW simulation to estimate the impact of a withdrawal using traditional modeling techniques. The prototype described in this paper has been used as the basis for the development of a production system currently in use by the Utah Division of Water Rights (Automated Groundwater Models, 2013). This system utilizes fifteen different MODFLOW models, including the Northern Utah Valley model. The time and effort required to perform an impact simulation using this system is a tiny fraction of what it formerly took using a manual approach. This has allowed the UT-DWR to perform an impact analysis at a far higher percentage of the applications, resulting in the application of better science in the decision-making process.
One of the most significant features of the well-permitting system is that it is based on a scripting environment and therefore can easily be customized. Each groundwater model is unique, and the criteria used to evaluate permit applications can vary from aquifer to aquifer. In some cases, drawdown is the critical factor and in other cases changes in discharge to streams or springs is most critical. By modifying the geoprocessing workflow, the system can easily be customized for each model and circumstance. Furthermore, the output produced by the system can be tailored to meet the reporting and archiving needs of the agency.

One of the common criticisms of automated modeling frameworks is that they oversimplify the modeling process and allow inexperienced users to perform simulations without fully understanding the limitations inherent in the model and without the ability to recognize when the model fails to produce a reasonable result. While this is a valid concern, it can be reasonably argued that automated scripts can lead to a greater degree of quality control, not less. First of all, this is not an environment in which someone would build a new model from scratch. An experienced modeler must first build and calibrate the model and assist in designing the automated workflow. In designing the workflow, the modeler can select which parts of the model input can be changed by the script, which in this case is typically just the Well Package file. Furthermore, limits can be placed on pumping rates, screen depths, and locations of wells. Once the simulation results are imported, the script can be adapted to include any number of quality control checks, including checking for excessive drawdown at the edges of the model that violate boundary condition assumptions. By contrast, when a set of input files is modified on a frequent and repetitive basis via a manual approach, there is a greater likelihood that one may ignorantly or inadvertently modify the wrong input file, thereby corrupting all subsequent analyses. 


\section{References}

Ames, Daniel P., Horsburgh, Jeffery S., Cao, Yang, Kadlec, Jiří, Whiteaker, Timothy, Valentine, David, 2012. HydroDesktop: web services-based software for hydrologic data discovery, download, visualization, and analysis. Environ. Model. Softw. 37, 146-156, http://dx.doi.org/10.1016/j.envsoft.2012.03.013.

Automated Groundwater Models, 2013. Retrieved from 〈http://gis.waterrights.utah. gov/gwmodels/_new/RunModel2.asp $>$ (retrieved 23.08.13.).

Castronova, A.M., Goodall, J.L., Elag, M.M., 2013. Models as web services using the Open Geospatial Consortium (OGC) Web Processing Service (WPS) standard. Environ. Model. Softw. 41, 72-83. http://dx.doi.org/10.1016/J.Envsoft.2012.11.010.

Castronova, Anthony M., Goodall, Jonathan L., 2010. A generic approach for developing process-level hydrologic modeling components. Environ. Model. Softw. 25 (7), 819-825.

Cederberg, J.R., Gardner, P.M., Thiros, S.A., 2009. Hydrology of Northern Utah Valley Utah County, Utah, 1975-2005 U.S. Geological Survey Scientific Investigations Report. U.S. Geological Survey, p. 114.

Changming, Liu, Jingjie, Yu, Kendy, Eloise, 2001. Groundwater and its impact on the environment in the North China plain. Water Int. 26 (2), 265-272.

Diaz, L., Costa, S., Granell, C., Gould, M., 2007. Migrating geoprocessing routines to web services for water resource management applications. In: Proceedings of the Paper Presented at the 10th AGILE International Conference on Information Science, Aalborg, Denmark.

Dymond, R.L., Regmi, B., Lohani, V.K., Dietz, R., 2004. Interdisciplinary web-enabled spatial decision support system for watershed management. J. Water Resour. Plan. Manag. 130 (4), 290-300.

Galloway, David, Jones, David R., Ingebritsen, S.E., 1999. Land Subsidence in the United States. U.S. Geological Survey, Reston, Virginia.

GitHub, 2014. Cloud-based MODFLOW model for automated well permitting. Retrieved from 〈https://github.com/njones61/cageo-wellpermittingtool〉 (retrieved 22.12.14.).

Glenis, Vassilis, Mc.Gough, Andrew Stephen, Kutija, Vedrana, Kilsby, Chris, Woodman, Simon, 2013. Flood modelling for cities using cloud computing. J. Cloud Comput. 2 (7).

Google, 2014. Google Maps API. Retrieved from 〈https://developers.google.com/ maps/faq\#usagelimits (retrieved 22.12.14.).

Horsburgh, Jeffery S., Tarboton, David G., Maidment, David R., Zaslavsky, Ilya, 2008 A relational model for environmental and water resources data. Water Resour. Res. 44, W05406.

Horsburgh, Jeffery S., Tarboton, David G., Piasecki, Michael, Maidment, Zaslavsky, David R., Ilya, Valentine, David, Whitenack, Thomas, 2009. An integrated system for publishing environmental observations data. Environ. Model. Softw. 24
(8), 879-888.

Jones, David J., 2012. A Server-Based Tool for Automating MODFLOW Simulations for Well Permitting Decision Support (MS). Brigham Young University.

Jones, Norman L., Lemon, Alan M., Gallup, Doug, 2010a. Automated well permitting using Arc Hydro Groundwater. In: Proceedings of the Paper Presented at the AWRA Spring Specialty Conference, Orlando, Florida.

Jones, Norman L., Strassberg, Gil, 2008. A GIS-based MODFLOW data model. In: Proceedings of the Paper Presented at the MODFLOW \& More 2008: Ground Water and Public Policy Conference, 19-21 May 2008, Golden, Colorado.

Jones, Norman L., Strassberg, Gil, Gallup, Doug, 2011. MODFLOW scripting via ArcGIS geoprocessing tools. In: Proceedings of the Paper Presented at the MODFLOW and More 2011: Integrated Hydrologic Modeling, 5-8 June 2011, Golden, Colorado.

Jones, Norman L., Strassberg, Gil, Lemon, Alan M., 2010b. Automated well Permitting via GIS geoprocessing tools. In: Proceedings of the Paper Presented at the World Environmental and Water Resources Congress: Challenges of Change, Providence, Rhode Island.

Konikow, Leonard F., Kendy, Eloise, 2005. Groundwater depletion: a global problem. J. Hydrogeol. 13, 317-320. http://dx.doi.org/10.1007/s10040-004-0411-8.

Liu, Yong, Xu, Yan, Ye, Wenming, 2010. ModflowOnAzure: an on-demand "Groundwater Modeling as a Service" solution. In: Proceedings of the Paper Presented at the 2010 IEEE International Conference on Cloud Computing Technology and Science, November 30-December 3, 2010, Indianapolis, IN.

Oulidi, Hassane Jarar, Löwner, Ralf, Benaabidate, Lahcen, Wächter, Joachim, 2012 HydrIS: an open source GIS decision support system for groundwater management (Morocco). Geo-spat. Inf. Sci. 12 (3), 212-216.

Refsgaard, J.C., Højberg, A.L., Møller, I., Hansen, M., Søndergaard, V., 2010. Groundwater modeling in integrated water resources management-visions for 2020. Ground Water 48 (5), 633-648.

Strassberg, Gil, 2005. A Geographic Data Model for Groundwater Systems (Ph.D. thesis). The University of Texas at Austin, Austin, Texas.

Strassberg, Gil, Jones, Norman L., 2010. Arc hydro groundwater data model and tools: overview and use cases. AQUAmundi 1 (2), 101-114.

Strassberg, Gil, Jones, Norman L., Maidment, David R., 2007. A geographic data model for representing ground water systems. Ground Water 45 (4), 515-518.

Strassberg, Gil, Jones, Norman L., Maidment, David R., 2011. Arc Hydro Groundwater: GIS for Hydrogeology. ESRI Press, Redlands, California.

Tillman, Fred D., Leake, Stanley A., Flynn, Marilyn E., Cordova, Jeffrey T., Schonauer, Kurt T., 2007. An online interactive map service for displaying ground-water conditions in Arizona National Water Availability and Use Program. Unites States Geological Survey, p. 16. 